\title{
Bur open Risk factors for stress fracture in female endurance athletes: a cross-sectional study
}

\author{
Rachel L Duckham, ${ }^{1}$ Nicholas Peirce, ${ }^{2}$ Caroline Meyer, ${ }^{3}$ Gregory D Summers, ${ }^{4}$ \\ Noël Cameron, ${ }^{1}$ Katherine Brooke-Wavell ${ }^{1}$
}

To cite: Duckham RL, Peirce N, Meyer C, et al. Risk factors for stress fracture in female endurance athletes: a cross-sectional study. BMJ Open 2012;2:e001920. doi:10.1136/bmjopen-2012001920

- Prepublication history and additional material for this paper are available online. To view these files please visit the journal online (http://dx.doi.org/10.1136/ bmjopen-2012-001920).

Received 10 August 2012 Accepted 11 October 2012

This final article is available for use under the terms of the Creative Commons Attribution Non-Commercial 2.0 Licence; see http://bmjopen.bmj.com

\footnotetext{
${ }^{1}$ Centre for Global Health and Human Development, Loughborough University, SSEHS, Loughborough, Leicestershire, UK ${ }^{2}$ Nottingham University Hospitals NHS Trust/England and Wales Cricket Board, Loughborough, UK ${ }^{3}$ Centre for Research into Eating Disorders (LUCRED), Loughborough University, Loughborough, UK ${ }^{4}$ Royal Derby Hospitals NHS Foundation Trust, Derbyshire, UK
}

Correspondence to Dr Rachel Duckham; r.l.duckham@lboro.ac.uk

\section{ABSTRACT}

Objective: To identify psychological and physiological correlates of stress fracture in female endurance athletes.

Design: A cross-sectional design was used with a history of stress fractures and potential risk factors assessed at one visit.

Methods: Female-endurance athletes (58 runners and 12 triathletes) aged $26.0 \pm 7.4$ years completed questionnaires on stress fracture history, menstrual history, athletic training, eating psychopathology and exercise cognitions. Bone mineral density, body fat content and lower leg lean tissue mass (LLLTM) were assessed using dual-x-ray absorptiometry. Variables were compared between athletes with a history of stress fracture (SF) and those without (controls; $C$ ) using $\chi^{2}$, analysis of variance and Mann-Whitney $\mathrm{U}$ tests.

Results: Nineteen (27\%) athletes had previously been clinically diagnosed with SFs. The prevalence of current a/oligomenorrhoea and past amenorrhoea was higher in SF than $C(p=0.008$ and $p=0.035$, respectively). SF recorded higher global scores on the eating disorder examination questionnaire $(p=0.049)$ and compulsive exercise test $(p=0.006)$ and had higher LLLTM ( $p=0.029)$ compared to $C$. These findings persisted with weight and height as covariates. In multivariate logistic regression, compulsive exercise, amenorrhoea and LLLTM were significant independent predictors of SF history $(p=0.006,0.009$ and 0.035 , respectively).

Conclusions: Eating psychopathology was associated with increased risk of SF in endurance athletes, but this may be mediated by menstrual dysfunction and compulsive exercise. Compulsive exercise, as well as amenorrhoea, is independently related to SF risk.

\section{INTRODUCTION}

Stress fractures (SFs) occur when microdamage caused by repetitive mechanical load exceeds the biological capacity of the bone. ${ }^{1}$ SFs are the most common overuse injury in athletes, interrupting training and prematurely ending sporting careers. ${ }^{2}$ Over $40 \%$ of

\section{ARTICLE SUMMARY}

Article focus

- To identify the factors related to stress fracture in female endurance athletes.

- To evaluate the associations of eating and exercise behaviours with stress fracture and to determine whether associations are independent of previously recognised risk factors.

Key messages

- Compulsive exercise and lower leg lean tissue mass, as well as amenorrhoea, are independently related to stress fracture risk.

- Eating disorder psychopathology was associated with increased risk of stress fracture in endurance athletes, but this may be mediated by menstrual dysfunction and compulsive exercise.

Strengths and limitations of this study

- Strength; the assessment of the Compulsive Exercise test and a more robust measure of eating psychopathology determined that compulsive exercise and eating psychopathology are associated with stress fracture risk.

- Limitation, potential recruitment bias, selfreporting of the history of stress fracture and the ability to recall data.

- Limitation; measurements at variable intervals following stress fracture during which time athlete behaviours, and other risk factors, may have changed.

athletes report a history of SF according to some previous research, although prevalence differs markedly between studies. ${ }^{3-5}$

Risk factors for SF have been studied in military recruits commencing physically demanding physical training programmes. The risk factors identified have included irregular menses; low bone mineral density (BMD); low lean mass, lower muscle size and strength; poor skeletal alignment (leg length discrepancy); narrow tibial cross-sectional area and low physical fitness compared to those who did not $\mathrm{SF}^{6-9}$ While these studies have improved our 
understanding of the aetiology of SF, these risk factors may not translate well to athletes, who are accustomed to training and have high levels of fitness. ${ }^{2}$ In female athletes, previously identified risk factors for SF include small calf circumference, late age at menarche, menstrual dysfunction (both past and current), low bone density, current disordered eating and abnormal gait. ${ }^{2} 5$ 10-15 However, findings have often been inconsistent (eg, low bone density is associated with increased risk in some studies but not others)..$^{5}$

Female endurance athletes have particularly high prevalence of the female athlete triad, which involves menstrual dysfunction, low BMD and dietary restriction/ energy deprivation. ${ }^{16}$ All these may be risk factors for SFs, ${ }^{12} 1315$ but previous studies on their role in athletic populations have had small sample sizes and yielded conflicting findings. ${ }^{5} 17$ Increased awareness of the female athlete triad in recent decades may have affected the management of female athletes, perhaps to the extent that the associations reported in older studies may no longer persist. The current high prevalence $(1-62 \%)^{18}$ of disordered eating among female athletes could further increase SF risk, as restrictive eating patterns were associated with increased risk in some of the previous studies. ${ }^{2} 1920$ Furthermore, restrictive eating patterns may be accompanied by compulsive exercise behaviours, ${ }^{21}{ }^{22}$ but the role of compulsive exercise has not been examined. Eating behaviours may have an independent effect on SF risk, or this may be mediated through related exercise behaviours, menstrual dysfunction or low bone density. It is important to determine whether eating behaviours have an independent effect as this would demonstrate that resolving menstrual dysfunction and low bone density would not entirely resolve the increased risk of SF.

There is thus a need for further research on the role of eating and exercise behaviours in SF risk, using multivariate models to determine whether risk factors act independently. Therefore, this study aimed to identify the factors related to SF in female endurance athletes, to evaluate associations of eating and exercise behaviours with $\mathrm{SF}$ and to determine whether associations are independent of previously recognised risk factors.

\section{METHODS AND MEASUREMENTS \\ Study design}

A cross-sectional design was used with a history of SFs and potential risk factors assessed at one visit. Questionnaires were completed to assess SF history, eating psychopathology, dietary intakes, menstrual dysfunction, contraceptive use and training history. A 4-day diet diary was provided for subsequent completion and return. BMD, bone mineral content (BMC), geometric properties and body composition were measured using dual-energy x-ray absorptiometry (DXA) and anthropometric measures were taken using standard techniques. The study received ethical approval from the National
Research Ethics Service and Loughborough University Ethics Committee. All athletes gave written informed consent.

\section{Participants}

Seventy female endurance athletes aged 18-45 years were recruited through the English Institute of Sport, UK athletics, British triathlon and UK-registered running and triathlon clubs, via letters, posters, group meetings and word-of-mouth. Athletes were required to, be competing at international, national or county level and training approximately 8-10 (runners) or $15-20 \mathrm{~h} /$ week (triathletes) in events from $800 \mathrm{~m}$ to the marathon or triathlon. Athletes were excluded from the study if they had not been trained in the last 6 months and if they were currently pregnant or lactating or had been in the last 12 months.

\section{Injury history}

History of SF was assessed by a questionnaire. These were defined as a fracture/reaction clinically diagnosed by a sports physician and confirmed with a positive diagnosis on x-ray, CT or MRI. For each SF, athletes recorded the age when the SF occurred, the anatomical location, time of the year and the method of diagnosis.

\section{Menstrual function}

Participants were classified as secondary amenorrhoeic (less than 4 menses per year) oligomenorrhoeic (4-9 periods/year, periods occurring at intervals greater than 35 days after onset of menses) or eumenorrhoeic (10 or more periods per year) based on their menstrual function in the last 12 months. ${ }^{23}$ For analysis purposes, athletes who were classified with menstrual dysfunction were combined into one group (a/oligomenorrhoea, 0-9 periods/year) ${ }^{24-26}$ and compared with the eumenorrhoeic athletes. Age at menarche, number of periods in the preceding 12 months, duration of a/oligomenorrhoea since menarche and current use of hormonal contraception (HC) were assessed by a questionnaire.

\section{Eating psychopathology and compulsive exercise cognitions}

Athletes completed the Eating Disorder Examination Questionnaire (EDE-Q) ${ }^{27}$ and the Compulsive Exercise Test (CET) ${ }^{17}$ The EDE-Q is a self-reported version of the EDE, the current gold standard for measuring eatingdisordered psychopathology. ${ }^{27}$ The EDE-Q is a 36-item questionnaire comprising four subscales (restraint, eating concern, shape concern and weight concern), a global score and a specific section of diagnostic questions related to bingeing/purging. Each item on the questionnaire is scored from 0 to 6 with high scores representative of concerns with eating behaviours and attitudes. The CET is a 24-item self-reported questionnaire scored from 0 to 5 with high scores representative of compulsive exercise traits. It is designed to assess four domains of compulsive exercise (compulsivity, affect regulation, 
weight-driven and shape-driven exercise and behavioural rigidity). ${ }^{17}$ The CET has not previously been used in competitive athletes but has been validated in a comparable group of young female exercisers. ${ }^{17}$

\section{Dietary behaviours}

Participants completed a food frequency questionnaire (European Prospective Investigation into Cancer; EPIC FFQ) ${ }^{28} 29$ and a 4-day diet diary. The EPIC FFQ provides general information of the number of portions consumed of a wide range of foods over the past 12 months. The 4-day food diary was completed by the participants over 3 week days and 1 weekend. The FFQ and the 4-day diet diary were coded and entered into a computerised software package (CompEat Pro, V.5.8) to determine energy, macronutrient and micronutrient intakes.

\section{Bone and body composition}

DXA was used to measure BMD and BMC of the total body, lumbar spine, femoral neck and radius (Lunar Prodigy, GE Healthcare, Madison, Wisconsin, USA V.12.2). Bone geometry at the femoral neck was estimated using Lunar Advanced Hip Structural Analysis (AHA) algorithms to determine the cross-sectional moment of inertia (CSMI), cross-sectional area (CSA), minimal femoral neck width and section modulus $(\mathrm{Z})$. All scans were conducted on the dominant side as this is reported to be the most prevalent side for injury. ${ }^{13}$

\section{Anthropometric measures}

Height and body mass were measured prior to the DXA measurements using standard protocols, via a stadiometer (Holtain Ltd, Pembrokeshire) and beam balance scale (Herbert and Sons Ltd, London), respectively. Body composition (mass of fat, lean and bone) was assessed from a total body DXA scan. The mass of bone-free lean tissue in the lower leg (LLLTM; defined as the region inferior to the knee joint space) was also determined from the DXA scan, as a measure related to calf muscle mass. Athletes were blinded to the body composition results until the end of the study to prevent any possible bias when answering questionnaires related to eating psychopathology. Circumferences of the dominant thigh and calf were measured with a tape measure held horizontally at the midpoint between the inguinal crease and the patella for the thigh, and midpoint between the proximal tibia border and the medial malleolus for the calf. ${ }^{30}$

\section{Statistical analysis}

All statistical analyses were performed using SPSS V.18.0 (SPSS, Chicago, Illinois, USA). The KolmogorovSmirnov test was used to assess normal distribution. Athletes were classified into two groups: those with a history of SF and a control (C) group. Potential risk factors were compared between groups using analysis of variance (ANOVA) and Mann-Whitney $U$ tests. $\chi^{2}$ Tests were used to determine whether frequencies of categorical variables differed between $\mathrm{SF}$ and $\mathrm{C}$ groups. Discriminators of SF identified as statistically significant in univariate analyses along with theory-driven variables weight (as a measure for body size) and training duration were entered into a logistic regression to determine their independent contribution to $\mathrm{SF} /$ reaction injury. The first model (model A) examined the contribution of a/oligomenorrhoea. Subsequent models (models B, C and D) examined the contributions of CET and EDE-Q independent of a/oligomenorrhoea and/or each other. The final model (model E) includes all potential discriminators of SF to determine which ones are independent of each other. For this analysis, eating psychopathology and compulsive exercise variables were recoded into two subgroups using a median split. Statistical significance was considered at the 5\% probability level $(\mathrm{p}<0.05)$.

\section{RESULTS}

Seventy female athletes (58 runners and 12 triathletes) were recruited, of whom $36 \%$ were at of national or international standard. A high prevalence of menstrual dysfunction was evident, with $42.9 \%$ of athletes categorised as a/oligomenorrhoeic ( $\leq 9$ periods/year) and $57.1 \%$ eumenorrhoeic ( $\geq 10$ periods/year). Of the 70 athletes, 21 (30\%; 4 a/oligomenorrhoeic and 17 eumenorrhoeic) were currently using HC.

Nineteen athletes $(27 \% ; 24 \%$ at the national/international level and $29 \%$ at the subelite level) reported having experienced a total of 24 SFs. Common SF sites were the metatarsals $(46 \%)$, tibia or fibula $(38 \%)$, calcaneus (13\%) and the femur (4\%). The mean (SD) age at the first SF was 21.4 (1.4) years, with SFs diagnosed at a median (IQR) of 3.0 (6.8) years from the start of training. Age, height, body mass and body fat did not differ between SF and C groups ( $p>0.05$; table 1$)$.

The prevalence of current a/oligomenorrhoea and past amenorrhoea were significantly higher in the SF than in the $\mathrm{C}$ group ( $\chi^{2}$ test $\mathrm{p}=0.008$ and 0.035 , respectively; table 1) although age at menarche did not differ significantly between groups. Dominant LLLTM was significantly higher in the $\mathrm{SF}$ than in the $\mathrm{C}$ group ( $p=0.029)$; this finding persisted after adjustment for weight $(\mathrm{kg})$ and training duration (hours/week) ( $p=0.035)$. Calf circumference measurements, bone measurements, energy, macronutrient intakes and calcium intakes did not differ between groups (table 1).

The SF group scored higher on the global scores for both the EDE-Q and CET Global score ( $p=0.049$, $\mathrm{p}=0.006$ respectively, table 2 ) and had a higher behaviour rigidity score on the CET $(\mathrm{p}=0.038)$ than controls (table 2). There were no significant differences in global scores for either, EDE- $Q(p=0.216)$ and CET $(p=0.216)$ between the athletes at the national/international level and subelite level.

The variables that differed according to SF in the univariate analysis, (current a/oligomenorrhoea, LLLTM, 
Table 1 Characteristics of athletes according to stress fracture (SF) history: mean (SD)

\begin{tabular}{|c|c|c|}
\hline Characteristics & SF group $(n=19)$ & Control $(C)$ group $(n=51)$ \\
\hline Age (years) & $25.6(6.4)$ & $26.1(7.8)$ \\
\hline Height $(\mathrm{m})$ & $1.67(0.05)$ & $1.67(0.05)$ \\
\hline Weight (kg) & $56.2(4.8)$ & $54.9(6.2)$ \\
\hline Body fat $(\%)$ & $16.6(4.7)$ & $17.4(6.4)$ \\
\hline Lower leg lean tissue mass $(\mathrm{kg})$ & $2.61(0.03)$ & $2.46(0.02)$ \\
\hline Calf circumference $(\mathrm{cm})$ & $32.0(2.3)$ & $31.2(1.80)$ \\
\hline Time since stress fracture (years; median (IQR)) & $2.0(3.0)$ & - \\
\hline \multicolumn{3}{|l|}{ Training } \\
\hline Time since commencing training (years) & $7.4(4.3)$ & $7.8(6.4)$ \\
\hline Age at commencing competition (years) & $18.3(7.0)$ & $18.4(8.5)$ \\
\hline Weekly training duration (hours/week) & $14.2(4.3)$ & $12.1(4.3)$ \\
\hline \multicolumn{3}{|l|}{ Bone mineral density $\left(\mathrm{g} / \mathrm{cm}^{2}\right)$} \\
\hline Total body & $1.160(0.070)$ & $1.151(0.064)$ \\
\hline Femoral neck & $1.068(0.122)$ & $1.089(0.107)$ \\
\hline Lumbar spine & $1.144(0.157)$ & $1.119(0.099)$ \\
\hline \multicolumn{3}{|l|}{ Bone mineral content $(\mathrm{g})$} \\
\hline Total body & $2482(305)$ & $2425(298)$ \\
\hline Femoral neck & $4.9(0.4)$ & $5.1(0.7)$ \\
\hline Lumbar spine & $60.5(12.2)$ & $60.2(9.9)$ \\
\hline \multicolumn{3}{|l|}{ Bone geometry } \\
\hline $\operatorname{CSA}\left(\mathrm{mm}^{2}\right)$ & $154(17)$ & $157(21)$ \\
\hline Minimal femoral neck width (mm) & $28.9(2.6)$ & $28.4(2.1)$ \\
\hline Section modulus $\left(\mathrm{mm}^{3}\right)$ & $677(117)$ & $674(121)$ \\
\hline \multicolumn{3}{|l|}{ Menstrual history } \\
\hline Age at Menarche (years) & $13.9(1.7)$ & $14.1(2.1)$ \\
\hline History of amenorrhoea† & $15(78.9 \%)$ & $26(51.0 \%)$ \\
\hline Current a/oligomenorrhoea† & $13(68.4 \%)$ & $17(33.3 \%)$ \\
\hline Current eumenorrhoea† & $6(31.6 \%)$ & $34(66.7 \%)$ \\
\hline \multicolumn{3}{|l|}{ Hormonal contraception } \\
\hline Current hormonal contraception users $†$ & $4(21.1 \%)$ & $17(33.3 \%)$ \\
\hline Current hormonal contraception use in a/oligomenorrhoea (HCA)† & $4(21.1 \%)$ & $3(64.7 \%)$ \\
\hline Four-day diet analysis & SF $(n=17)$ & $C(n=44)$ \\
\hline Energy intake (kcal) & $1862(688)$ & $1875(365)$ \\
\hline $\mathrm{CHO}(\%)$ & $55.2(5.3)$ & $56.6(5.3)$ \\
\hline Protein (\%) & $14.8(2.9)$ & $16.2(3.3)$ \\
\hline Fat $(\%)$ & $30.0(4.9)$ & $27.2(5.3)$ \\
\hline Calcium (mg) & $887(377)$ & $944(277)$ \\
\hline
\end{tabular}

*Significant difference between stress fracture and control groups: $p<0.05$.

†Reported as the number of people and percentage.

EDE-Q scores and CET scores) were entered into a multiple logistic regression adjusted for weight $(\mathrm{kg})$ and training duration (hours/week). A/oligomenorrhoea was associated with 4.7 -fold greater odds of $\mathrm{SF}$ relative to eumenorrhoea $(\mathrm{p}=0.009$, table 3 , model $\mathrm{A})$. This finding persisted when current $\mathrm{HC}$ was entered into the regression model $(\mathrm{p}=0.012, \mathrm{~B}=1.506)$ and when $\mathrm{CET}$, EDE-Q and/or LLLTM were added to the model (table 3, models B-E). CET score and LLLTM, but not EDE-Q scores contributed to SF risk independent of a/oligomenorrhoea. Athletes with CET scores above the median had 7.1-fold greater odds of past SF than those below the median $(p=0.006, B=1.956$; table 3 models $B$ and D). Each additional SD of LLLTM was associated with 2.3-fold greater odds of fracture $(\mathrm{p}=0.035, \mathrm{~B}=0.843)$. Findings for all models were similar when not adjusted for weight and training duration.

\section{DISCUSSION}

Eating psychopathology, compulsive exercise, menstrual dysfunction and LLLTM were associated with increased $\mathrm{SF}$ risk in endurance athletes. The association of eating psychopathology was not independent of menstrual function, suggesting that the influence of disordered eating on SF is mediated through a/oligomenorrhoea. Compulsion to exercise and LLLTM, as well as 
Table 2 Eating disorder examination and compulsive exercise test questionnaire responses according to stress fracture history: median (IQR)

\begin{tabular}{lll}
\hline Characteristics & $\begin{array}{l}\text { Stress fracture } \\
\text { group }(\mathrm{N}=19)\end{array}$ & $\begin{array}{l}\text { Control }(\mathbf{C}) \\
\text { group }(\mathrm{N}=51)\end{array}$ \\
\hline EDE-Q & $1.6(0.6-3.2)$ & $1.0(0.4-1.8)$ \\
$\quad$ Restraint & $0.6(0.2-1.4)$ & $0.2(0.2-0.6)$ \\
Eating concerns & $1.9(0.9-3.6)$ & $1.3(0.5-2.0)$ \\
Shape concerns & $1.2(0.6-3.0)$ & $1.0(0.4-1.8)$ \\
Weight concerns & $1.7(0.6-2.7)$ & $0.9(0.5-1.6)^{*}$ \\
Global scores & & \\
CET & $3.4(2.6-3.9)$ & $2.8(1.9-3.5)$ \\
Compulsive exercise & $2.4(1.8-3.4)$ & $2.0(1.6-2.6)$ \\
Shape and weight & $4.0(3.4-5.0)$ & $3.8(3.0-4.4)$ \\
Mood regulation & $0.7(0.0-1.3)$ & $0.3(0.0-1.0)$ \\
Lack of exercise & & \\
enjoyment & $3.7(3.0-4.0)$ & $3.0(2.7-3.7)^{*}$ \\
Behaviour rigidity & $2.9(2.4-3.1)$ & $2.4(2.1-2.8)^{*}$ \\
$\quad$ Global scores &
\end{tabular}

*Significant difference between stress fracture and control groups: Mann Whitney-U test $\mathrm{p}<0.05$

EDE-Q, Eating Disorder Examination Questionnaire; CET, Compulsive Exercise Test.

menstrual dysfunction, were independently related to SF risk and may play a role in SF aetiology.

In this study, $27 \%$ of female athletes had a history of SF. This is similar to the prevalence of $31 \%$ in a recent study in female cross-country runners, ${ }^{20}$ but substantially lower than the $50 \%$ in a classic study in endurance athletes. ${ }^{2}$ Differences in findings could be explained by factors such as: diagnostic techniques, athlete age, training intensity and volume and potential recruitment bias. It is also possible that findings from earlier studies, and increased awareness of female athlete triad, have led to improvements in athlete management contributing to lower prevalence of SF in more recent studies. In our study, as in a recent study in distance runners, ${ }^{31}$ the most common site was the metatarsals, while in earlier studies more SFs occurred at the tibia in distance runners ${ }^{2} 332$ and track and field athletes, ${ }^{2} 3263334$ although metatarsal and tarsal SFs were more common in sprinters and jumpers. ${ }^{32}$ Metatarsal SF prevalence is associated with changes in training surface, training volume, footwear and running biomechanics, ${ }^{35}$ so these factors may contribute to differences in $\mathrm{SF} /$ reaction locations.

Current menstrual dysfunction was prevalent in this sample of athletes, with $43 \%$ of athletes reporting current amenorrhoea or oligomenorrhoea. Both current and past menstrual dysfunction were significantly more frequent in athletes with a history of SF, consistent with earlier findings. $^{2} 10113637$ Furthermore, current menstrual dysfunction was an independent predictor of SF history, with a/oligomenorrhoeic athletes having 4.3 times greater odds of SF compared with those who were currently eumenorrhoeic. This is consistent with the 6-fold greater odds of SF in athletes with menstrual dysfunction reported by Bennell et al. ${ }^{2}$ The endurance

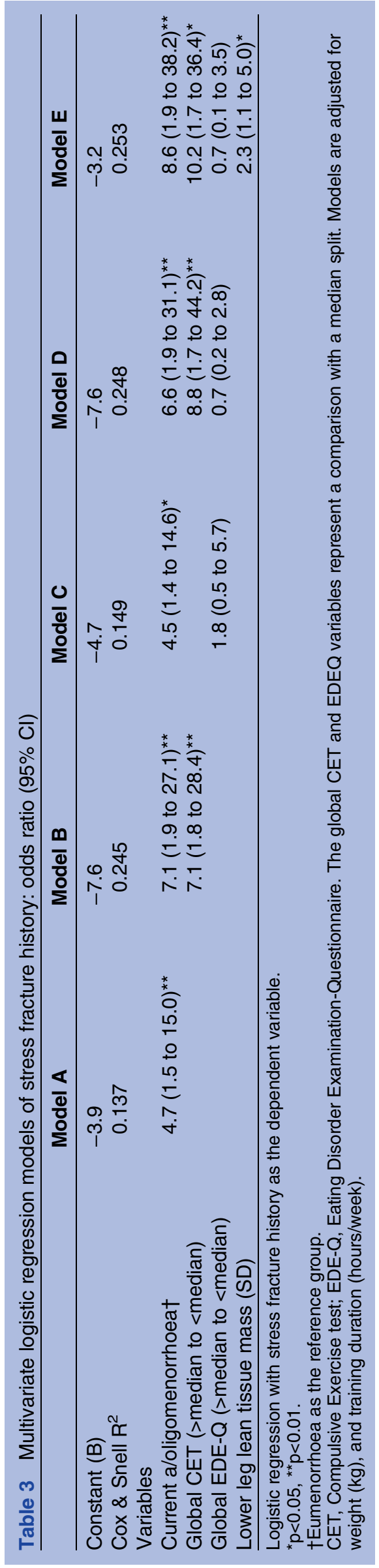


athletes had an average menarcheal age of 14 years, compared with 12.3 years in a broader population indicating later menarche occurs in endurance athletes, as has previously been reported in gymnasts. ${ }^{38}$ Age at menarche was not associated with an increased risk of SF, although associations have been reported in some ${ }^{213} 39$ although not all ${ }^{1120}$ previous studies. As the results did not identify significant differences in either age at menarche or current BMD, it seems most likely that secondary amenorrhoea rather than primary amenorrhoea or delayed menarche was associated with SF.

Interestingly, although athletes with SF had a higher prevalence of amenorrhoea, they had a lower prevalence of hormonal contraceptive use, although this difference did not reach statistical significance. It is possible that amenorrhoea not countered by $\mathrm{HC}$ use is associated with greater SF risk; furthermore, amenorrhoeic athletes are possibly less likely to comply with HC use in the fear of gaining weight. ${ }^{40}$ Alternatively it is possible that having a history of SF influences HC-prescribing strategies. Given the increased awareness of the female athlete triad, clinical physicians presented with an amenorrhoeic athlete with a SF may attempt to determine the cause of, and resolve, the amenorrhoea rather than prescribing $\mathrm{HC}$, although past research has shown a trend towards a reduction in SF when HC was prescribed. ${ }^{1126}{ }^{40}$ Further studies on the role of $\mathrm{HC}$ use in SF are needed.

Athletes with a history of SF scored higher on the EDE-Q than athletes with no SF history, thus demonstrating a potential relationship with eating psychopathology. This finding supports earlier work which used a less robust measure of eating psychopathology. ${ }^{2}$ However, unlike previous studies ${ }^{2}$ our findings did not show eating psychopathology to be a discriminator of SF history independent of a/oligomenorrhoea. The relationship between eating psychopathology and SF may therefore be mediated through menstrual dysfunction. Future intervention studies would be necessary to confirm whether treatment of disordered eating can reduce SF risk.

A novel finding from the present study is that athletes with high (above median) CET scores had moderately (7.3 times) greater odds of SF, perhaps indicating a greater tendency to train through discomfort. Compulsive exercise predicted SF independent of a/oligomenorrhoea and eating psychopathology. It is therefore important to examine compulsive exercise, as well as menstrual status, when identifying athletes at risk of SF.

Lower calf circumference has been reported to increase the risk of SF in track and field athletes independent of all other factors ${ }^{13}$ and this finding is assumed to be mediated by the lower leg muscle mass. In this study, calf circumference did not differ according to SF history, but LLLTM measured by DXA was positively related with SF, with athletes who had a greater lower leg lean and running more being more likely to have had an SF, independent of other risk factors. Due to the retrospective nature of this study, however, it is not possible to determine if greater LLLTM is a cause or effect of SF history. Future studies should further examine the potential role of lower leg muscularity in SF aetiology using more robust measures than calf circumference, for instance DXA or MRI.

Factors not significantly related to SF in this study included dietary intakes, BMD, bone geometry and calf circumference. Low dietary calcium intake was a significant predictor of SF in some, ${ }^{20}$ but not all ${ }^{13}$ previous research. Findings may differ depending on measurement tools and differences in dietary intakes, although the mean calcium intake was above the recommended values in all these studies. Similarly, low BMD was associated with SF risk in some ${ }^{131520}$ but not all previous studies. ${ }^{210}$

Strengths of this study include the assessment of CET. Our findings that compulsive attitudes towards exercise and eating psychopathology are associated with SF risk highlight that those treating and coaching endurance athletes should consider attitudes to exercise and eating behaviours when assessing SF risk. Future research should examine whether interventions that address these features can reduce SF risk. The major limitation of this study is imposed by the experimental design. Due to the crosssectional nature of this study, it is not possible to determine whether risk factors are a cause or effect of the SF as they have been measured after the outcome occurred. Also, as the study was not prospective we could not determine relative risks. It should be noted that as the prevalence of SFs is relatively high, ORs may be substantially greater than relative risks. Further limitations include potential recruitment bias, self-reporting of the history of SF and the ability to recall data. However, the occurrence of a SF during an athlete's career is usually an event of such significance that it is unlikely to be misreported. Athletes were measured at variable intervals following SF during which time their behaviours, and other risk factors, may have changed. Differences in SF site and prevalence between recent and classic studies suggest that changes in athlete management have occurred (perhaps following findings from earlier studies), so there is a need to conduct further prospective studies in contemporary female endurance athletes.

In conclusion, disordered eating was associated with an increased risk of SF, but this may be mediated through menstrual dysfunction. Compulsive exercise cognitions, as well as amenorrhoea, were independently associated with SF risk and may have a role in SF aetiology.

Contributors RLD and KBW were responsible for the study design, data collection, statistical analysis, interpretation, reporting and manuscript preparation and are the guarantors. NP, CM, GDS and NC contributed to the study design, interpretation and manuscript preparation.

Funding This research was funded by Loughborough University School of Sport, Exercise and Health Sciences and East Midlands Universities Association.

Competing interests None.

Ethics approval National Research Ethics Service (NRES).

Provenance and peer review Not commissioned; externally peer reviewed.

Data sharing statement There are no additional data available. 


\section{REFERENCES}

1. Schaffler MB, Radin EL, Burr DB. Long term fatigue behavior of compact bone at low strain magnitude and rate. Bone 1990;11:321-6.

2. Bennell KL, Malcolm SA, Thomas SA, et al. Risk-factors for stress-fractures in female track and field athletes-a retrospective analysis. Clin J Sport Med 1995;5:229-35.

3. Bennell KL, Malcolm SA, Thomas SA, et al. The incidence and distribution of stress fractures in competitive track and field athletes-a twelve-month prospective study. Am J Sports Med 1996;24:211-17.

4. Nattiv A, Puffer JC, Casper J, et al. Stress fracture risk factors incidence and distribution: a 3 year prospective study in collegiate runners. Med Sci Sports Exerc 2000;32(5 Suppl):S347.

5. Snyder RA, Koester MC, Dunn WR. Epidemiology of stress fractures. Clin Sports Med 2006;25:37-52.

6. Milgrom C, Giladi M, Simkin A. Analysis of the biomechanical mechanisms of tibial stress fractures among Israeli infantry recruits. Clinl Orthop 1988;231:216-21.

7. Beck TJ, Ruff CB, Shaffer RA, et al. Stress fracture in military recruits: gender differences in muscle and bone susceptibility factors. Bone 2000;27:437-44.

8. Beck T. Measuring the structural strength of bone with dual-energy $\mathrm{x}$-ray absorptiometry: principals, technical limitations, and future possibilities. Osteoporos Int 2003;14(Suppl 5):S81-8.

9. Giladi M, Milgrom C, Simkin A, et al. Stress fractures-identifiable risk factors. Am J Sports Med 1991;19:647-52.

10. Carbon R, Sambrook PN, Deakin V, et al. Bone-density of elite female athletes with stress-fractures. Med J Australia 1990;153:373-6.

11. Myburgh $\mathrm{KH}$, Hutchins J, Fataar $\mathrm{AB}$, et al. Low bone density is an etiologic factor for stress-fractors in athletes. Ann Intern Med 1990;113:754-9.

12. Bennell K, Matheson G, Meeuwisse W, et al. Risk factors for stress fractures. Sports Med 1999;28:91-122.

13. Bennell KL, Malcolm SA, Thomas SA, et al. Risk factors for stress fractures in track and field athletes-a twelve-month prospective study. Am J Sports Med 1996;24:810-18.

14. Brukner P, Bradshaw C, Bennell K. Managing common stress fractures-let risk level guide treatment. Physician Sportsmed 1998;26:39-47.

15. Nattiv A. Stress fractures and bone health in track and field athletes. J Sci Med Sport 2000;3:268-79.

16. Nattiv A, Loucks AB, Manore MM, et al. American College of Sports Medicine position stand. The female athlete triad. Med Sci Sports Exerc 2007;39:1867-82.

17. Taranis L, Touyz S, Meyer C. Disordered eating and exercise: development and preliminary validation of the compulsive exercise test (CET). Eur Eat Disord Rev 2011;19:256-68.

18. Sundgot-Borgen J, Torstveit $M$. The female football player, disordered eating, menstrual function and bone health. Brit J Sports Med 2007;41:68-72.

19. Nattiv A, Armsey TD. Stress injury to bone in the female athlete. Clin Sports Med 1997;16:197-224.
20. Kelsey JL, Bachrach LK, Procter-Gray E, et al. Risk factors for stress fracture among young female cross-country runners. Med Sci Sports Exerc 2007;39:1457-63.

21. Meyer C, Taranis L, Goodwin H, et al. Compulsive exercise and eating disorders. Eur Eat Disord Rev 2011;19:174-89.

22. Davis $\mathrm{C}$, Kennedy $\mathrm{SH}$, Ravelski E, et al. The role of physical activity in the development and maintenance of eating disorders. Psychol Med 1994;24:957-67.

23. Snow-Harter CM. Bone health and prevention of osteoporosis in active and athletic women. Clin J Sports Med 1994;13:389-404.

24. Snead DB, Stubbs CC, Weltman JY, et al. Dietary patterns, eating behaviours, and bone mineral density in women runners. Am J Clin Nutri 1992;56:705-11

25. Myburgh $\mathrm{KH}$, Bachrach LK, Lewis B, et al. Low bone mineral density at axial and appendicular sites in amenorrheic athletes. Med Sci Sports Exerc1993;25:1197-202.

26. Barrow GW, Saha S. Menstrual irregularity and stress fractures in collegiate female distance runners. Am J Sports Med 1988;16:209-16.

27. Fairburn CG, Beglin SJ. Assessment of eating disorders-interview of self-reporting questionnaire. Int J Eat Disord 1994;16:363-70.

28. Welsh AA. The CAFE computer program for nutritional analysis of the EPIC-Norfolk food frequency questionnaire and identification of extreme nutritient values. J Hum Nutr Diet 2005;18:99-116.

29. Bingham SA, Gill C, Welch A, et al. Comparison of dietary assessment methods in nutritional epidemiology-weighed records $\mathrm{V} 24-\mathrm{H}$ recalls, food frequency questionnaires and estimated-diet records. Brit J Nutr 1994;72:619-43.

30. Callaway C, Chumlea W, Bouchard C, et al. Circumferences. Anthropometric standardization reference manual. Champaign, IL: Human Kinetics, 1988: 39-54.

31. Arendt E, Agel J, Heikes C, et al. Stress injuries to bone in college athletes-a retrospective review of experience at a single institution. Am J Sports Med 2003;31:959-68.

32. Benazzo F, Barnabei G, Ferrario A, et al. Stress fractures in track and field athletics. J Sports Traumatol 1992;14:51-65

33. Bennell KL, Brukner PD. Epidemiology and site specificity of stress fractures. Clin Sports Med 1997;16:179-95.

34. Matheson GO, Clement DB, McKenzie DC, et al. Stress fractures in athletes-a study of 320 cases. Am J Sports Med 1987;15:46-58.

35. Crossley K, Bennell KL, Wrigley T, et al. Ground reaction forces, bone characteristics, and tibial stress fracture in male runners. Med Sci Sports Exerc 1999;31:1088-93.

36. Grimston SK, Zernicke RF. Exercise-related stress responses in bone. J Appl Biomech 1993;9:2-14.

37. Warren MP. Amenorrhea in endurance runners. J Clin Endocrinal Metab 1992;75:1393-7.

38. Malina R, Bouchard C. Characteristics of young athletes. Growth maturation, and physical activity. Champaig, IL: Human Kinetics, 1991: 443-63.

39. Carbon RJ. Exercise, amenorrhoea and the skeleton. Brit Med Bull 1992;48:546-60.

40. Cobb KL, Bachrach IK, Sowers M, et al. The effect of oral contraceptives on bone mass and stress fractures in female runners. Med Sci Sports Exerc 2007;39:1464-73. 